\title{
EDITORIAL
}

\section{Neonatal latex allergy}

\section{Journal of Perinatology (2007) 27, 533-534; doi:10.1038/sj.jp.7211795}

Latex allergy and hypersensitivity reactions are well-known complications for pediatric patients undergoing multiple surgical procedures. Largely, the concern for latex allergy in neonatal intensive care was confined to patients presenting with myelomeningocoele. However, during the past 10 years there has been a markedly expanding knowledge base about human allergic reactions to natural rubber latex. In part, this expanded information base has been driven by a broadening clinical awareness of at-risk patients and recognition of the ubiquity of health care supplies and household items that contain latex. Concomitantly, there has been increasing knowledge about the molecular basis for human immunoreactivity to latex proteins.

The incidence of latex allergy in the general population has been estimated to be $0.7 \%$, up to $17 \%$ among all health care providers, and as much as $65 \%$ in patients with myelomeningocoele beyond the first year of life. ${ }^{1}$ Although spina bifida patients constitute the majority of pediatric latex allergic patients, it can now be assumed that a considerable number of infants in neonatal intensive care units are at risk of developing latex allergy. The case report by Wynn et al. ${ }^{2}$ in this issue of the Journal provides readers with a neonatal presentation of immediate latex hypersensitivity reaction and a previously unrecognized in-hospital source for latex protein exposure. It is important to understand the variability of latex sensitivity in the newborn and sick infant population. Current understanding suggests that exposure to latex bearing products soon after birth contributes to the magnitude of the hypersensitivity in spina bifida patients. However, as demonstrated by Wynn et al., ${ }^{2}$ other neonates can be similarly affected early on. A recent report by Eiwegger et $a l^{3}$ underscores the observations of Wynn and co-workers with the findings of latex-specific immunoglobulin E(IgE) antibodies in a cohort of postoperative neonatal surgery patients, which revealed antibodies in 16/35 (46\%) of spina bifida patients, $1 / 20(5 \%)$ of gastroschisis/omphalocoele patients and 4/45 (8.9\%) of either posthemorrhagic or congenital hydrocephalus patients.

Latex allergy may present simply as erythema of the skin with or without itching, as an eczematous atopic rash or as hives and urticaria. Respiratory signs may include rhinitis, wheezing or outright bronchospasm with stridor. Depending on the nature of exposure to latex proteins, any of the various reactions may persist chronically or precipitously develop into hypotension and anaphylaxis. Latex allergic reactions can be categorized as:
(1) immediate hypersensitivity, the most dangerous and life threatening; (2) latex contact urticaria, involving itching, and hives, developing in 15 or more minutes after exposure, such as gloving; (3) allergic contact dermatitis, as an atopic rash, developing 1 to 2 days after exposure and thought to be a contact dermatitis secondary to additive materials used in compounding latex; or (4) irritant dermatitis secondary to chemicals used in processing the raw natural rubber latex. ${ }^{4}$ It is worth noting that the subject in this Journal case report exhibited many of the signs of latex allergy but with longer response times, limited intensity and, fortunately, without progressing to anaphylaxis. Perhaps, these were a manifestation of the immature but susceptible newborn immune response.

Latex allergens originate from natural rubber latex gathered from the sap of the plant Hevea brasiliensis. A family of hevien proteins has been identified as those which form reactive epitopes with IgE. A particular hevein protein (Hev b 6.02) has been singled out as the major component of latex immediate hypersensitivity reactions. The importance to these findings is that isolation of the specific proteins responsible for latex allergy may afford future therapeutic approaches such as blocking antibodies or even vaccination in extreme cases of latex allergy. ${ }^{5}$ Moreover, specific latex protein identification is being studied of improving upon skin prick testing and the radio-allergo sorbent test. Both tests have serious limitations as to sensitivity and specificity.

At present, there are two measures for the prevention of inadvertent exposure of infants to latex sensitization. The first is careful history taking from the mother for known latex allergy and that of other family members, followed by bedside identification and notices of latex allergy risk. This is especially needed for all patients with congenital anomalies that will require immediate and subsequent surgeries such as the spina bifida patients and others as mentioned above, as well as patients with urogenital anomalies, tracheo-esophageal fistula, imperforate anus and cleft palate.

The second measure to prevent latex exposure is the assurance that hospital-wide precautions are in place for providing latex-free materials to the neonatal intensive care unit. More assuring would be hospital-wide policies for a latex-free environment. It is noteworthy that all newborns can be exposed to skin and mucous membrane sensitization beginning in the delivery room, as well as those entering an intensive care setting. ${ }^{6}$ Emphasis for hospital-wide precautions for latex allergy prevention is found in the study by Nieto et $\mathrm{al}^{7}$. wherein they followed all infants with spina bifida from birth through the sixth year after institution of 
hospital-wide latex-free policies and procedures. Primary sensitization of newborn spina bifida patients decreased from 26.7 to $4.5 \%$. However, broad acceptance of the need to be actively changing to preventive procedures is lagging. Abd El-Atti et al. ${ }^{8}$ reported in 2006 from the University of Pittsburgh Medical Center, a 100 institution, 50 state survey of hospital pharmacy practices for identifying latex-allergic patients and for policies and procedures used in preparing parenteral medications. They reported that the majority of hospitals responding were either unaware of the need or did not have specific institutional pharmacy policies in effect for the protection of patients at risk for latex allergy. Programs to establish latex-free facilities require more than just changing to low-latex protein non-powdered gloves. A hospital-based latex-free program should have a nurse and physician team responsible for instituting protocols, implementation, monitoring outcomes, providing testing services and availing allergy clinic follow-up services for affected patients.

Finally, the ubiquity of latex-sensitizing agents must be recognized for infants and health care workers in the hospital environment, and inadvertent sensitization in home health care services, emergency transport services and the general home environment. Certain foods may elicit a latex-allergy response such as melon, avocado, potato, tomato and banana. Common items in an infant's room at home may contain latex components such as toys (especially balloons), bottle nipples, pacifiers, nasal bulb syringes and clothing with elastic. All of these possibilities, besides hospital devices such as ventilator equipment, ventriculo- peritoneal shunts, catheters of all kinds and purposes as well as lipid emulsion vial caps.

MD Cunningham

Division of Neonatal-Perinatal Medicine, Department of Pediatrics, University of California, Irvine Medical Center,

Orange, CA, USA

E-mail:Dcunningham65@aol.com

\section{References}

1 Agarwal S, Gawkrodger DJ. Latex allergy: a health care problem of epidemic proportions. Eur J Dermatol 2002; 12: 311-315.

2 Wynn RJ, Boneberg A, Lakshminrusimha S. Unexpected source of latex sensitization in a neonatal intensive care unit. J Perinatol 2007; 27: 586-588.

3 Eiwegger T, Dehlink E, Schwindt J, Pomberger G, Reider N, Frigo E et al. Early exposure to latex products mediates latex sensitization in spina bifida but not in other diseases with comparable latex exposure rates. Clin Exp Allergy 2006; 36: 1242-1246.

4 Sicklick MJ. www.iVillageTotalHealth.com 2006.

5 Reyes-Lopez CA, Hernandez-Santoyo A, Pedrza-Escalona M, Mendoza G, HernandezArana A, Rodriquez-Romero A. Insights into a conformational epitope of Hev b 6.02 (hevein). Biochem Biophys Res Commun 2004; 314: 123-130.

6 Worth J. Neonatal sensitization to latex. Med Hypotheses 2000; 54: 729-733.

7 Nieto A, Mazon A, Pamies R, Lanuza A, Munoz A, Estornell F et al. Efficacy of latex avoidance for primary prevention of latex sensitization in children with spina bifida. J Pediatr 2002; 140: 370-372.

8 Abd El-Atti S, Martinelli B, Yourich B, Wasicek K, Weber R. Nationwide survey of hospital practices when compounding parenteral nutrition solutions in latex-allergic patients. Nutr Clin Pract 2006; 21: 513-517. 